\title{
DEBATES
}

\section{O Sistema Partidário no Paraná: do Personalismo à Estruturação}

\author{
The Paranás Party System: from Personalism to Structuration
}

\section{Luiz Domingos Costa Bruno Bolognesi}

\section{Resumo}

O trabalho procura identificar as características gerais do sistema partidário no estado do Paraná, isto é, sua evolução, principais organizações e tendências sistêmicas. O objetivo é demonstrar que o ambiente de personalismo e fragmentação crescente não foram obstáculos para estruturar o sistema em torno do antagonismo histórico entre duas frentes partidárias, protagonizadas por PMDB/PT e PSDB/DEM. Dessa forma, sugerimos que o personalismo das principais lideranças estaduais, uma vez consolidado em campos ideológicos opostos, caminhou lentamente em direção à polarização da disputa nacional e pode definir as alternativas de policies no estado, em torno das quais orbitaram regularmente parte dos partidos relevantes no cenário local. O movimento incessante do PDT entre esses dois blocos é a contra-face da estruturação do sistema, que reserva uma dose de abertura de entrada e saída nos blocos para os partidos que não alcançam capacidade de formulação de políticas e promoção de candidaturas competitivas.

\section{Palavras chave}

Partidos; Sistema Partidário; Eleiçôes Majoritárias; Política Estadual; Paraná.

\begin{abstract}
This work seeks to identify general characteristics of the party system of the state of Paraná, Brazil, i.e., its evolution, main organisations and systemic trends. The text aims at demonstrating that the environment of personalism and growing fragmentation were no obstacles to the system's consolidation around the historical antagonism between PMDB/PT and PSDB/DEM. In doing so, we suggest that once the personalism of the most important leaders at the state level was consolidated in opposite ideological fields, it slowly moved towards the polarisation of the national dispute, becoming able to define state policies around which regularly orbited some of the parties that are relevant in the local scenario. The never-ceasing PDT's movement between these two blocs is the counter side of the system, which reserves some space for entering and exiting of the blocks for those parties that do not achieve the capacity of formulation of policies and the promotion of competitive candidates.
\end{abstract}

\section{Keywords}

Political Parties; Party System; Majority Elections; Regional Policy; Paraná. 


\section{Introdução}

Ao descrever o Paraná da década de 1990, Barry Ames manifestou sua desilusão: "O regionalismo exacerbado confere à política paranaense uma natureza quase apolítica [...]. De certo modo, as características dos líderes do Paraná sugerem que existe algo de peculiar na sociedade paranaense" (AMES, 2003, p. 151-152). Para essa imagem revelar ao menos parcialmente a política paranaense, é preciso que tenhamos em conta o funcionamento dos partidos e do sistema partidário. Afinal, as elites aqui se comportam de modo não competitivo em partidos indiferenciados? Temos um sistema partidário excessivamente regionalizado e que não se conecta com o sistema nacional de partidos?

Ao examinar os poucos trabalhos dedicados ao estudo dos partidos políticos no Paraná, emerge uma imagem típica de sociedades pretorianas: o estado parece encerrar um caso clássico de subdesenvolvimento partidário. As razóes apontadas para isso compreendem: i) o excesso de personalismo dos governantes frente às organizações partidárias (CERVI E CODATO, 2006; CERVI, 2006); ii) a fraqueza das lealdades partidárias (LEPRE, 2000; SANTOS, 2001); e iii) a persistência das redes familiares sobre fracas fronteiras partidárias (OLIVEIRA, 2007).

Pretendemos explorar a história política do estado por meio da reconstituição do desenvolvimento do sistema partidário para responder quantas e quais foram as forças políticas capazes de controlar o executivo estadual, bem como qual é o tipo de competição estabelecida entre essas forças. Além disso, pretendemos explorar a quantidade de partidos que tem obtido representação política relevante e, finalmente, se a província paranaense tem um formato de funcionamento partidário apartado das clivagens políticas dominantes na política nacional.

$\mathrm{O}$ artigo está organizado da seguinte forma: após apresentar uma discussão propositiva sobre classificação de sistemas partidários em nível subnacional, as evidências serão desmembradas em duas seções: uma sobre a variação e fragmentação do sistema partidário paranaense; outra sobre a história das disputas ao governo estadual no Paraná. Nas conclusões, sistematizamos o argumento desenvolvido ao longo do artigo de que o quadro partidário paranaense apresenta características muito similares ao nacional: aumento da fragmentação e estruturação sistêmica, cuja marca é o antagonismo entre dois blocos partidários, PMDB/PT (Partido do Movimento Democrático Brasileiro/Partido dos Trabalhadores) versus PSDB/DEM (Partido da Social Democracia Brasileira/ Democratas). 


\section{O sistema partidário: classificações e subunidades}

As proposições duvergenianas ainda são centrais na temática sobre partidos políticos. As leis de Duverger (1980), por maior que fosse seu poder preditivo e geral, foram modificadas, alteradas, suavizadas, mas sempre teve como critério de fundo o número de partidos políticos. Apesar da imprecisáo numérica que animou a polêmica, não há, até hoje, consenso acerca de qual sejam os melhores critérios para classificar e avaliar ${ }^{1}$ o desempenho dos sistemas partidários ao redor do mundo ${ }^{2}$.

As principais interpretaçôes que tentaram abandonar o caráter de 'lei' das proposições de Duverger são de Laakso e Taagepera (1979), Sartori (1982) e Taagepera e Shugart (1989). Para os três trabalhos, não é possível tomar a determinação do sistema majoritário de volta como único vetor do bipartidarismo e tampouco o multipartidarismo como fruto de sistemas de dois turnos ou proporcionais. A intenção dos autores, se podemos resumir o argumento, é que as leis duvergenianas devem ser entendidas como hipóteses ou como uma tendência geral.

Contudo, a quantificação do número ideal de partidos para classificar sistemas em muito ou pouco fragmentados ainda encontra debate na literatura (REBELLO, 2012). São poucos os trabalhos que pretendem uma análise que leve em conta outros critérios políticos, ideológicos ou comportamentais para a classificação dos sistemas de partidos ${ }^{3}$.

No Brasil, nos últimos anos, temos acompanhando uma polarização entre dois grandes partidos na disputa presidencial. Meneguello (2010) e Melo (2010) sugerem que as disputas entre líderes políticos nacionais podem produzir consequências estruturantes nos sistemas de partidos das subunidades. Mesmo chegando num ponto diferente do que iremos sinalizar, alguns autores (SAMUELS e ABRÚCIO, 2000; MIRANDA, 2009; BOHN e FERREIRA, 2009; SANTOS,

\footnotetext{
1 É importante notar que outra série de estudos estiveram preocupados não somente com a classificação e e análise dos sistemas partidários, mas também com sua institucionalização. Questão esta inaugurada por Pedersen (1979).

2 Talvez a única exceção à regra de que o sistema eleitoral seria determinante para a configuração do sistema partidário pode ser encontrada em Colomer (2003). O autor propõe a inversão da lei de Duverger ao analisar mais de 200 eleições em 87 países. Segundo Colomer (idem), há uma tendência geral ao longo do tempo para que todos os sistemas se tornem de representação proporcional se aumentam o número de partidos efetivos e que os sistemas eleitorais majoritários são na verdade fruto de um sistema partidário de pluralismo moderado.

${ }^{3}$ Mais uma vez a exceção a isto pode ser encontrada no excelente texto de Dumont e Caulier (2005). Os autores utilizam o poder de votação nos parlamentos para estabelecer o número efetivo de partidos legislativos. Mesmo que não ocorra uma aproximação com uma nova classificação de sistemas partidários, os autores mobilizam outros indicadores para contar partidos.
} 
2013) têm se esforçado para mostrar um alinhamento - que pode ocorrer por razóes diferentes ${ }^{4}$ - entre o sistema partidário da disputa nacional com os sistemas regionais. O denominador que une estes estudos está focado no comportamento do eleitor e, invariavelmente, está preocupado com os alinhamentos das elites políticas que, fazendo uso da terminologia sartoriana, utilizariam os partidos como organizaçóes de aluguel para promover seus interesses. Santos (2013, p. 14) lembra sabidamente: "mais importante e antes dos eleitores, contariam as disposiçóes e as alianças das lideranças partidárias municipais”. Não estamos propondo aqui chegar ao menor nível das unidades federativas, mas sim nos governos estaduais com o mesmo objetivo: demonstrar que o comportamento estratégico das legendas independe de critérios formais, sendo preciso avançar para análises onde qualitativamente se derive o peso destas alianças políticas frente à polarização nacional constatada.

Diante disso, o número efetivo de partidos parece insuficiente para captar dinâmicas políticas que não se traduzem a partir, somente, do sistema eleitoral. A suposta polarização entre PT e PSDB no nível da disputa presidencial parece, segundo o critério de número efetivo de partidos, não fazer sentido quando miramos os planos subnacionais. Contudo, poucos autores mobilizam o conceito sartoriano de partido relevante para uma análise que combine critérios qualitativos e quantitativos ao classificar o sistema partidário. Segundo o autor (SARTORI, 1982), partido relevante é aquele que consegue atrair para sua órbita uma quantidade de pequenos outros partidos que náo conseguem ter força eleitoral e conquistarem cadeiras sozinhos; seria o partido ou os partidos que são capazes de determinar a natureza do sistema:

\footnotetext{
${ }^{4}$ Por exemplo, para Samuels e Abrúcio (2000) é possível dizer que no Brasil existe um gubernatorial coattail effect, onde o comportamento dos partidos nas eleiçôes estaduais (para Assembléias e Câmara) é diretamente impactado pelo arranjo das eleições majoritárias do mesmo distrito. Por outro lado, para Santos (2013), esse alinhamento das eleiçōes locais com as nacionais não seria fruto de um presidential coattail effect, mas sim do aparelhamento das máquinas políticas locais promovida pelo governo federal.
} 
[...] a questão real não é se o número de partidos é importante - ele é mas se o critério numérico de classificação nos permite lançar mão sobre o que realmente importa. Até agora, a resposta é, claramente, não. E a razão preliminar é igualmente clara: nenhum sistema contábil pode operar sem regras de contagem. Se recorrermos à contagem, devemos saber como contar. Mas somos incapazes até mesmo de decidir quando um é um e quando dois é dois - se o sistema é ou não bipartidário. Com isso, damos um salto para o infinito, isto é, abrimos mão totalmente da contagem. Tendo sido incapazes de determinar quando dois é dois, cobrimos todo o resto, exaustos, dizendo apenas mais de dois. Não é de espantar, portanto, que a abordagem pelo número de partidos leve à frustração (SARTORI, 1982, p. 144-145).

Não se trata aqui de negar a relevância que os estudos que utilizam o número efetivo de partidos (no parlamento e nas eleiçóes) possuem para compreender a capacidade de estruturação na formulação de preferências eleitorais - um aumento efetivo no efeito psicológico de Duverger - dos sistemas partidários (CARREIRÃO, 2012). Para utilizar um exemplo fornecido pelo próprio Sartori (1982), podemos pensar que um sistema de partidos onde existam apenas dois partidos relevantes (ou efetivos, se estilizarmos o argumento apenas para o critério numérico) limita a possibilidade de interação em apenas um. Já um sistema onde existam cinco partidos as possibilidades de interaçáo cresce para dez, onde encontramos sete partidos as interações possíveis vão para vinte e um e assim por diante. Isso, certamente, tem consequências para a cristalização do efeito psicológico nas eleições seguintes e para a forma como os governos conduzem suas alianças políticas.

Ainda, apenas a análise numérica dos partidos que compóem um sistema deixa de perceber dinâmicas políticas que podem estar ligadas a arranjos políticos 'aninhados', para utilizar o termo de Melo (2010). O critério quantitativo mascara as alianças que os partidos realizam para disputar eleição, deixa de lado o peso que um partido pode ter no sistema partidário sem que o mesmo conquiste uma quantidade mínima, para se tornar efetivo, do voto popular. Ou pior, se olharmos apenas para o número de cadeiras, observamos que outros fatores como o quociente eleitoral, que é diretamente afetado pela magnitude distrital, pode esconder partidos que tenham papel relativamente central no interior de um dado sistema (NICOLAU e SCHMITT, 1995).

Portanto, a mobilização de um conceito que combine número de partidos e o peso relativo dos partidos entre si apresenta a vantagem de ir além do sistema eleitoral e partidário, permitindo a compreensão do sistema político como um todo. Sartori 
$(1982)^{5}$ sugere para que um partido possa ser classificado como relevante é preciso que ele acumule ao longo do tempo algumas características. Em primeiro lugar, o partido deve apresentar, em eleições seguidas, a capacidade de formar maioria em relação aos seus pares no parlamento em que disputa votos e cadeiras. Em segundo lugar, o partido deve desfrutar de 'capacidade de chantagem', ou seja, poder de barganha na montagem das coalizóes de governo quando assume o poder. Em terceiro lugar, é preciso que o partido tenha 'força política', que se refere, de acordo com Sartori (1982), ao potencial que um partido possui de atrair cadeiras suficientes para ser necessário dentro de uma coligação eleitoral. Essas três características de relevância mostram que mesmo diante de um cenário com elevado número de partidos, apenas alguns deles possuem condição de ter 'peso' político suficiente para serem classificados como relevantes.

Ainda na classificação de Sartori (1982), tratando especificamente dos sistemas multipartidários, caso do Brasil como um todo e também do Paraná, o autor apresenta cinco formas distintas de classificação para sistemas políticos competitivos ${ }^{6}$, sejam elas:

Pluralismo moderado: existe fragmentação política, mas coexiste baixa polarização ideológica. Existem alguns blocos de partidos, mas não podem ser interpretados como frutos de uma aliança ideológica ou programática de termos políticos e não existem partidos antissistema, dispostos a não jogar com as regras do jogo eleitoral.

Pluralismo polarizado: a fragmentação política é presente, contudo ocorre uma polarização em torno de legendas específicas. Sartori (1982) admite que toda polarização é ideológica ou programática. Nossa sugestão, no início deste artigo, é que tal polarização do sistema partidário nos dois níveis possa ocorrer por outra via, qual seja, a oposição e governo, numa estruturação do sistema partidário regional, para utilizar os termos de Sartori (1982).

Sistemas de partidos atomizados: como o nome sugere, não há qualquer tipo de polarização entre partidos. Aqui, cada partido desfruta poder individual de ser relevante num sistema completamente desestruturado.

\footnotetext{
${ }^{5}$ A classificação proposta por Sartori (1982) é, na verdade, uma combinação dos critérios de Duverger (1980) e dos critérios de competitividade propostos por Lapalombara e Weiner (1972).

${ }^{6}$ No interior dos sistemas políticos não competitivos temos o sistema partidário de partido único e o de partido hegemônico, este último onde a oposição é apenas formal e não existe rotatividade no poder.
} 
Sistemas bipartidários: é onde existe a possibilidade em que apenas dois partidos possam competir entre si, contudo um deles consegue maioria. Ainda, aqui se vislumbra a chance de que ocorra alternância no poder.

Sistemas de partidos predominantes: um único partido é apoiado pela maioria dos eleitores e atrai maioria dos outros partidos, contudo existe a possibilidade de alternância no poder pela via da conquista de maiorias simples.

A tipologia sarotoriana carrega em si a vantagem de adicionar elementos extras, votos ou número de cadeiras para a classificação dos sistemas partidários. Contudo, ao impor a presença da polarização ideológica torna muito mais difícil sua operacionalização ${ }^{7}$. Na seção seguinte tentaremos mobilizar o papel da polarização entre líderes e coligações para qualificar o subsistema no estado do Paraná.

\section{O sistema partidário no Paraná: entre dispersão e estruturação}

A combinação entre arranjo institucional eleitoral e clivagens sociais seria a chave da explicação para a alta fragmentação partidária no Brasil. Como apontam Nicolau e Schmitt (1995) o sistema proporcional, a alta média da magnitude distrital e a clivagem social do país levariam a uma multiplicidade de partidos em todos os níveis da disputa. Aliado ao contexto social e institucional, fatores históricos como a ditadura militar criaram disputas internas nos partidos ora concentrados no bipartidarismo imposto de cima, ARENA (Aliança Renovadora Nacional) versus PMDB. Estes elementos são os principais fatores da fragmentação partidária no Brasil (REBELLO, 2012).

Não obstante, falar em fragmentação partidária não pode ser encarado automaticamente como causa de um sistema partidário fragmentado ou em subsistemas sem qualquer uniformidade. Apenas com o estabelecimento de critérios onde se pese quantitativamente, como no caso de Taagepera e Shugart (1989) ou de forma combinada, como em Sartori (1982), podemos afirmar que a simples existência de mais do que dois partidos disputando as eleiçôes não acarreta num multipartidarismo. Portanto, a análise mais detida de critérios como o número de votos, a capacidade de coligação e de barganha política é fundamental para analisarmos sistemas partidários ao redor do mundo.

Por outro lado, por que devemos focar em casos particulares como no estado do Paraná aqui apresentado? Em primeiro lugar, como já afirmamos, pela escassa

\footnotetext{
${ }^{7}$ Mais uma vez o exemplo do estudo de Dumont e Caulier (2005) é importante como alternativa. Contudo, os autores mobilizam apenas indicadores parlamentares e confere pouca atenção a real função do sistema de partidos como estruturador das preferências eleitorais, como uma espécie de atalho cognitivo para a decisão do voto.
} 
contribuição que a literatura traz acerca da lógica partidária-eleitoral neste estado. Porém, mais importante do que agregar novos dados, a tipologia de Sartori (1982) carrega consigo a necessidade de uma análise detida nos casos onde ocorrem condições específicas em subsistemas. Em segundo lugar, pois, metodologicamente, num estado onde se esperaria a completa ausência de qualquer estruturação do sistema partidário nos parece interessante para análise. Ora, seria muito mais provável que encontrássemos a polarização PSDB versus $\mathrm{PT}$ em locais onde esta disputa é clara e conta com os atores nominalmente envolvidos, como, por exemplo, o subsistema paulista ${ }^{8}$. Num estado caracterizado pelo provincianismo e personalismo político, como apontamos na introdução, seria muito mais difícil encontrar algum alinhamento polarizador, ainda que estivéssemos lidando para além da contabilidade de partidos políticos efetivos, eleitorais ou parlamentares. Em resumo, o caso do estado do Paraná é um locus privilegiado para investigarmos o possível alinhamento do sistema partidário regional em relação ao nacional.

A descentralização do sistema partidário brasileiro já foi contemplada por uma infinidade de pesquisas, especialmente, o caso brasileiro em seu agregado já foi devidamente debatido (FERREIRA, BATISTA e STABILE, 2008). Por outro lado, a descentralização do sistema partidário, levando a cabo as especificidades de cada estado, ainda está por ser feita. Usualmente, a descentralização do sistema partidário está em contraposição à desejada nacionalização sistêmica para uma coordenação eleitoral eficiente. Carmani (2004), contudo, aponta que o alinhamento dos sistemas partidários regionais, pode ser um indicador para que se verifique a consolidação do sistema partidário nacional. Assim, não basta apresentar indicadores agregados como, por exemplo, a volatilidade eleitoral comparada dos estados com a nacional (BOHN e FERREIRA, 2009). Seria preciso verificar nas unidades federativas as dinâmicas de cada partido ou das relações de competição interpartidárias.

Nesse sentido, o trabalho de Lima Jr. (1997) já oferece ao leitor uma perspectiva que enfatiza o contexto e a lógica política regional, mostrando que o arranjo institucional-legal não era suficiente para demarcar as diferenças entre os sistemas partidários tomados em cada estado da federação. Mesmo trabalhos que tentaram estabelecer levantamentos sistemáticos sobre os sistemas partidários estaduais (FERREIRA, BATISTA e STABILE, 2008; CORTEZ, 2009), não oferecem uma explicação acerca da estruturação ou não dos sistemas partidários subnacionais. Nossa hipótese é que tal explicação não é oferecida, pois demandariam

\footnotetext{
${ }^{8}$ No estado de São Paulo, PT e PSDB reproduziram a disputa nacional pelo menos nas últimas quatro eleiçóes.
} 
análises esmiuçadas sobre a competição política nas diferentes subunidades políticas da federação, impossibilitando uma conclusão que agregasse estados tão separados pelo arranjo federativo e lideranças regionalizadas.

Porém, náo nos parece acertado dizer que cada ente federativo opera numa lógica própria, institucional ou política. Mesmo fazendo a defesa da importância dos estudos pontuais, as dinâmicas que são adquiridas no decorrer da consolidação democrática não devem ser ignoradas em seu papel formador de preferências nos eleitorados estaduais.

Bardi e Mair (2008) estão entre aqueles que enfatizam as chamadas divisóes horizontais nos sistemas partidários. Em países com sistemas de governo descentralizados, típicos de países federados, essas divisóes são mais frequentes, dando espaço para que as dinâmicas regionais de competição possam criar sistemas partidários estaduais. $\mathrm{O}$ argumento central desta perspectiva é que as dinâmicas sociais e políticas nos estados tais como, níveis de desenvolvimento, formação cultural diversa ou diferentes processos de acomodação de elites políticas, poderiam levar a dinâmicas próprias que não seriam vistas ao analisarmos o país em seu agregado (MAINWARING e PÉREZ-LIÑAN, 2005).

Partindo da hipótese de que os subsistemas partidários estariam apresentando um alinhamento em relação à disputa nacional, observamos que o caso do estado do Paraná, isso é bastante evidente. Os dados acerca do número efetivo de partidos nas eleições (NEP) ${ }^{9}$ aumentam na mesma direção em que se aumenta a fragmentação do voto nas eleiçôes presidenciais.

\footnotetext{
9 Para o cálculo do número efetivo de partidos, eleitorais ou parlamentares, utilizamos a celebrada fórmula de Laakso e Taagepera (1979): 1/( $\left.\sum \mathrm{pe}^{2}\right)$, onde pe = percentual de cadeiras ocupadas por cada partido ou proporção de votos recebidos por cada partido, respectivamente.
} 
Gráfico 1 - Número efetivo de partidos eleitorais legislativos (1990-2010) 10

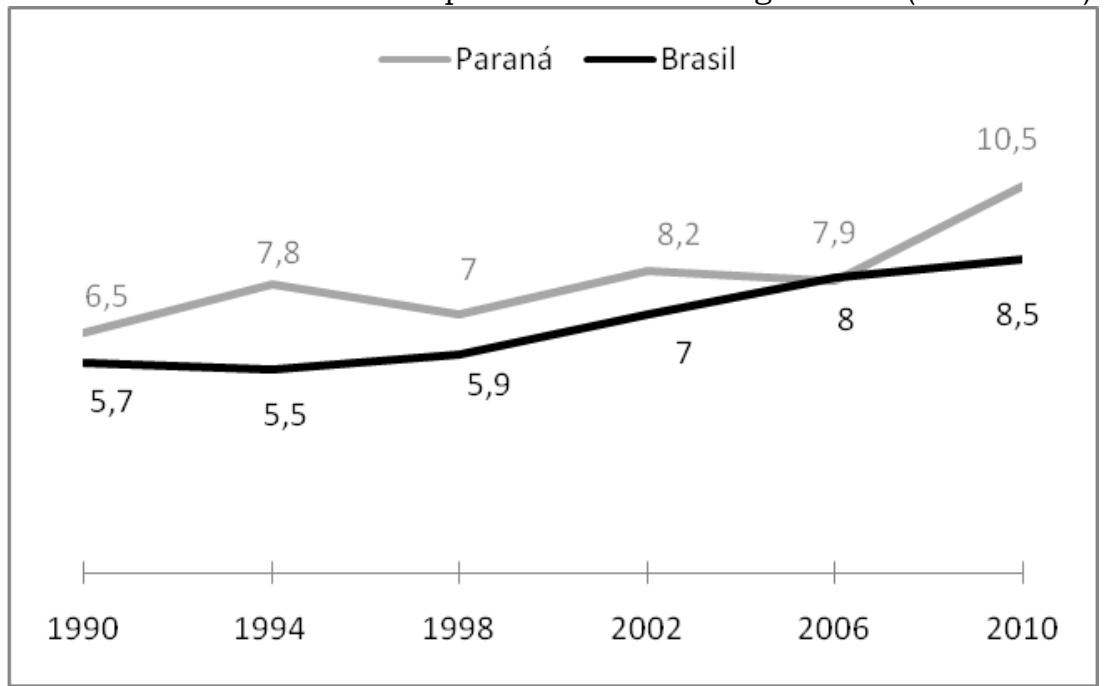

Fonte: Rebello (2012, p.13).

Conforme os dados do gráfico acima, podemos ver que existe uma tendência global no crescimento do número efetivo de partidos nas eleições nacional e estadual, no caso paranaense em especial. Esse primeiro dado ainda não sugere uma polarização entre governo e oposiçáo, como aventa nossa hipótese de pesquisa apresentada na introdução. Contudo, fornece elementos para pensarmos que o subsistema em questão acompanha as eleiçóes nacionais quando a questão é também o legislativo. Ainda que as lógicas majoritária e proporcional operem de formas distintas, onde poderíamos aventar a presença de um coattail effect, nossa intenção aqui é simplesmente demonstrar que os alinhamentos legislativos no estado não estáo radicalmente distantes do panorama nacional, operando numa lógica própria, como suporiam as afirmaçóes de Ames (2003).

Não se trata de um alinhamento puro e simples de lideranças políticas nacionais que se reflete nas disputas entre líderes regionais. Trata-se sim de uma tendência estruturadora do sistema de partidos como um todo via espaço de disputa política no plano superior. $\mathrm{O}$ crescimento no número de partidos eleitorais, dado pela quantidade de votos que o eleitor registra em cada legenda, tanto nas eleiçóes nacionais para a Câmara dos Deputados quanto nas paranaenses para a mesma casa, mostra que de 1990 até 2010 podemos observar um comportamento paralelo onde o

\footnotetext{
${ }^{10}$ Aqui estão contemplados os votos para as eleições legislativas federais no estado e número efetivo de partidos eleitorais para a Câmara dos Deputados no Brasil.
} 
estado do Paraná acompanha efeitos das campanhas e do aumento na fragmentação geral.

Porém, há um efeito da magnitude distrital sobre o sistema de partidos quando passamos a analisar não o número efetivo de partidos eleitorais, mas sim o de partidos parlamentares. A magnitude distrital cria um efeito conhecido como malapportionment, nada mais do que uma diferença entre a distribuição das cadeiras em relação à proporção de votos recebidos por um partido. Segundo Nicolau e Schmitt (1995), magnitude distritais menores tendem a beneficiar os maiores partidos, aqueles que concentram maior quantidade de votos. A elevação do quociente eleitoral em distritos de baixa magnitude poderia criar tal distorção de representação, tendo como resultado um favorecimento aos grandes partidos, o partisan bias (CAVALCANTE e TURGEON, 2012). Para evitar a comparação entre um estado de magnitude média, com 30 cadeiras como o Paraná, com o Brasil, onde a média da magnitude é de 18 assentos, comparamos abaixo a lógica que opera sobre tamanhos de bancadas semelhantes e num mesmo contexto político-social.

Gráfico 2 - Número efetivo de partidos parlamentares (ALEP) e bancada paranaense na Câmara dos Deputados $(1982$ - 2010)

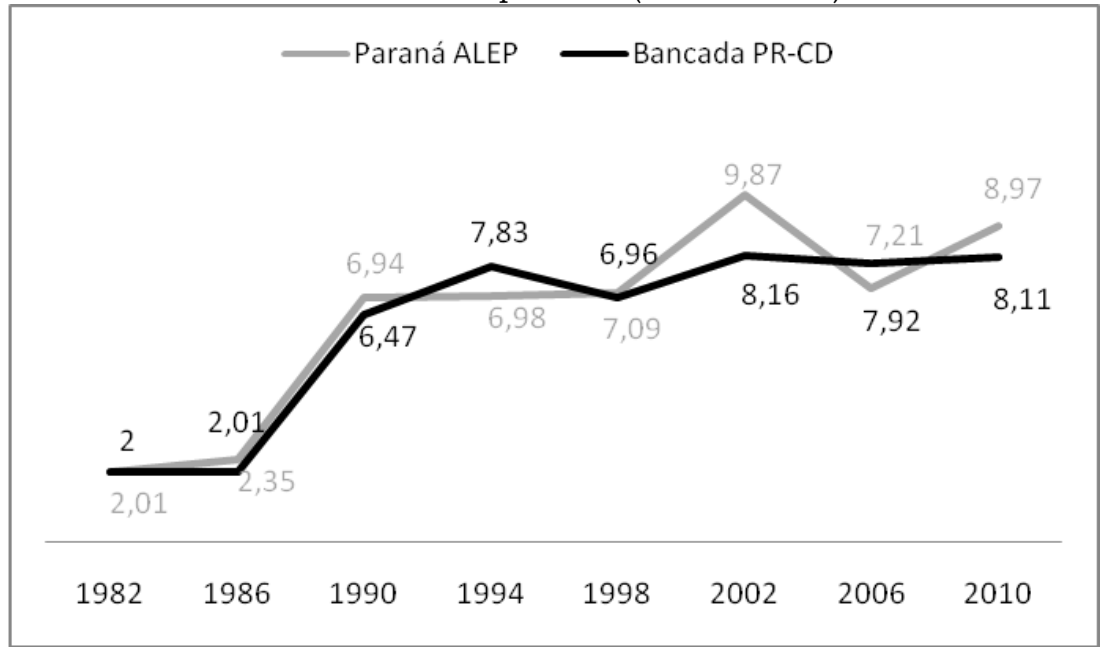

Fonte: Ferreira, Batista e Stabile (2008, p. 443) e TRE-PR (2013).

Já no Gráfico 2, o que observamos é um alinhamento global do comportamento do sistema partidário no plano estadual e a projeçáo deste plano ao nacional. O que podemos ver é que existe uma tendência muito clara de que os dois planos andem juntos. $\mathrm{O}$ argumento poderia estar no fato de que, disputando o mesmo eleitor, não haveria motivos para encontrarmos desalinhamento entre estas instâncias. Por outro lado, como estamos tratando de dois níveis de governo 
diferentes, esperaríamos encontrar aqui as divisões horizontais aventadas por Carmani (2004). Contudo, sabendo que a quantidade de cadeiras na disputa é semelhante, podemos dizer com alguma segurança que os dois níveis do sistema partidário paranaense encontram-se alinhados.

A alta fragmentação nos partidos parlamentares, tanto na Assembleia Legislativa, quanto na bancada paranaense na Câmara dos Deputados apresenta uma curva que indica uma estruturação da competição no estado, mesmo que aqui náo possamos falar em polarização tendo em vista números como mais do que oito partidos eleitorais efetivos nas duas casas nas eleições de 2010. A única coisa que os dados nos permitem dizer é que, dado controle sobre o tamanho das bancadas e o contexto político e institucional, o Paraná é congruente na formação de suas representações estadual e nacional.

Não obstante, é possível que essa congruência dos indicadores de NEP entre as duas bancadas paranaenses (estadual e federal) seja efeito de um comportamento singular, fruto de um componente localista congênito e desproporcional em relação ao padrão de fragmentação dos partidos no agregado nacional. O Gráfico 3 permite descartar essa hipótese ao colocar lado a lado os valores do NEP para a ALEP e para a Câmara dos Deputados em geral. A crescente fragmentação do sistema partidário local acompanha a tendência do sistema partidário nacional.

Gráfico 3 - Número Efetivo de Partidos Parlamentares - Assembleia Legislativa do Paraná e Câmara dos Deputados (1990-2010)

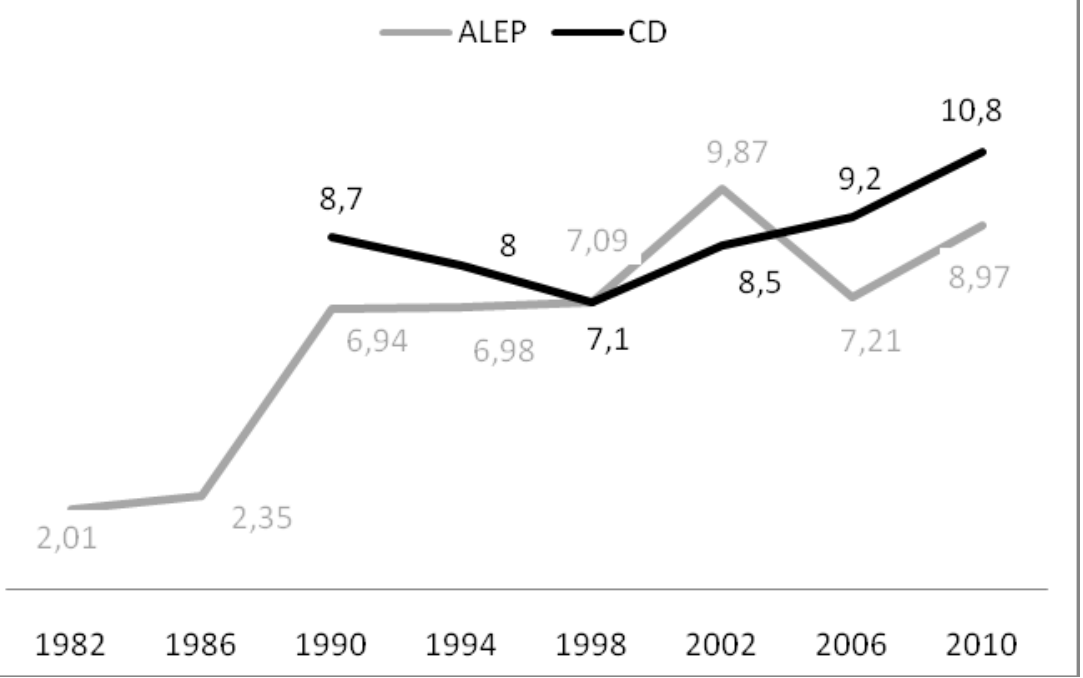

Fonte: Ferreira, Batista e Stabile (2008, p. 443), Rebello (2012, p. 8) e TRE-PR (2013). 
Em primeiro lugar, é preciso notar que as linhas do gráfico não estão mais tão próximas como no anterior. Porém, observando os dados com cuidado, a relação ente as duas esferas se mantêm. Se o alinhamento ocorre também no nível nacional, podemos pensar que a força da magnitude distrital não seja tão determinante para o desenho do sistema de partidos do Paraná. Quando observamos a existência de uma curva de crescimento da Assembleia Legislativa que acompanha o aumento na fragmentação partidária no nível nacional, independente do estado, podemos concluir existir uma lógica por trás desta análise que finda por criar algum corpo ao sistema de partidos regional. Ou seja, mesmo que ignoremos o efeito do partisan bias, encontramos que o estado acompanha o crescimento de partidos presentes na disputa nacional.

Em parte podemos responder a este encontro na fragmentação partidária pela lógica do voto do eleitor. Circunscritos no mesmo distrito eleitoral, as opçóes de competição postas pelos partidos legislativos são partilhadas pelo mesmo eleitorado. Assim, o sistema eleitoral isola os efeitos do sistema partidário a cada estado, onde todos são em alguma medida reféns dos padrões nacionais de estruturação.

Se isso ocorre de forma indiscriminada, eleições de outra natureza, como as majoritárias, a lógica da disputa nos governos estaduais seria ainda mais alinhadas à disputa presidencial.

Tabela 1 - Número efetivo de candidatos (NEC) ${ }^{11}$ no Paraná e no Brasil

\begin{tabular}{c|c|c|c|c|c|c|c|c}
\hline & $\mathbf{1 9 8 2}$ & $\mathbf{1 9 8 6}$ & $\mathbf{1 9 9 0}$ & $\mathbf{1 9 9 4}$ & $\mathbf{1 9 9 8}$ & $\mathbf{2 0 0 2}$ & $\mathbf{2 0 0 6}$ & $\mathbf{2 0 1 0}$ \\
\hline Paraná $^{12}$ & 1,9 & 1,8 & 3,3 & 2,2 & 2 & 4,4 & 2,9 & 2 \\
\hline Brasil $^{13}$ & - & - & 2,8 & 2,6 & 2,5 & 2,8 & 2,4 & 2,7 \\
\hline
\end{tabular}

r de Pearson $=0,617^{14}$

Fonte: TRE-PR (2013).

Como podemos observar na Tabela 1 , o número efetivo de candidatos ao governo, e que aqui não coincide com o de partidos eleitorais, guarda o mesmo traço ao longo do tempo do que nas disputas presidenciais. A diferença básica aqui é que o sistema de partidos em eleiçóes majoritárias oferece menor permeabilidade para novos atores (ROSE e MACKIE, 1988). Isso reduz drasticamente a quantidade de partidos,

\footnotetext{
${ }^{11}$ Para o cálculo do NEC foi contabilizado a proporção de votos que cada candidato e sua respectiva coligação receberam. O cálculo é o mesmo para o número de partidos efetivos eleitoral.

12 Eleiçôes para Governador do estado do Paraná.

${ }^{13}$ Eleiçôes para Presidente da República.

${ }^{14}$ Para NEC_PR*NEC_BR.
} 
aumentando o efeito mecânico de Duverger (1980). A associação moderadamente alta que encontramos nos dados, com $\mathrm{r}$ de 0,617 , sugere uma associaçáo positiva entre os valores, mesmo com uma quantidade de dados bastante reduzida para a realização de um teste de correlação.

De uma forma geral, com exceção à eleição de 2002 onde a disputa pelo governo do Paraná destoa da nacional, nossa hipótese de que o sistema partidário paranaense toma contornos da lógica nacional é verdadeira. Mesmo que tal hipótese seja pouco imperativa, é seguindo a sugestão de Sartori (1982) que imaginamos uma lógica política que pode dar ossatura a sistemas supostamente fragmentados.

Nesse caso específico, a polarização personalizada em torno dos candidatos de PT e PSDB à Presidência da República serve como uma baliza ou um catalisador para que subsistemas muito permeáveis, dotados de especificidades institucionais e líderes regionais ganhem traços de estruturação, polarizando a disputa com uma espécie de lógica de 'palanque' do sistema partidário. Ou seja, para que se consiga ter força dentro dos estados é preciso que se abra palanque eleitoral e recorra a alianças no nível nacional.

\section{Eleições e partidos nas disputas ao executivo do Paraná}

A história dos partidos políticos paranaenses desde a redemocratização tem um início que acompanha o padrão nacional: os partidos que herdam parte significativa dos quadros políticos da ARENA e do MDB (Movimento Democrático Brasileiro) dominaram as eleições de 1982 ao governo estadual. O PMDB venceu o PSD (Partido Social Democrático) elegendo José Richa governador. Desde então, muitas siglas foram criadas e o cenário de rápida fragmentação foi contrabalanceado pelo predomínio do PMDB nas eleições seguintes para praticamente todos os cargos em disputa ${ }^{15}$, elegendo também os governadores em 1986 (Álvaro Dias) e 1990 (Roberto Requião).

O primeiro ciclo peemedebista foi interrompido em 1994, quando o PDT(Partido Democrático Trabalhista) elegeu o ex-governador biônico e ex-prefeito da capital Jaime Lerner. Além do renome como urbanista, Lerner estabeleceu sua carreira política no seio da frente conservadora forjada durante o regime militar, sob a tutela de Ney Braga. Ao vencer a eleição para o governo estadual em 1994, Lerner derrotou o ex-governador Álvaro Dias, então filiado ao PP (Partido Progressista) (que surgiu da fusão entre o PST (Partido Social Trabalhista) e o PTR (Partido Trabalhista

\footnotetext{
${ }^{15}$ Alguns autores chegam a indicar que no Paraná dos anos 80 o PMDB teve um desempenho de partido hegemônico (CERVI e CODATO, 2006).
} 
Renovador)). No decorrer do seu primeiro mandato caminhou em direção à coalizão governista no plano federal, se transferindo para o PFL (Partido da Frente Liberal) em setembro de 1997, provocando uma intensa migração de políticos locais para esse partido. Em outubro de 1998, Lerner se reelege governador pelo PFL no primeiro turno, derrotando o seu principal adversário no estado, Roberto Requião. Do ponto de vista do quadro partidário, duas são as consequências da reeleição de Lerner pelo PFL do Paraná: crescimento meteórico experimentado pelo PFL paranaense em todo o estado no final dos anos 1990 (CERVI e CODATO, 2006) e seu reflexo com sinal invertido no declínio vertiginoso experimentado pelo PDT, que foi abandonado por muitos deputados (CERVI, 2006) e cujas forças só foram reativado anos mais tarde, mas nunca nos patamares do experimentado durante o primeiro governo lernista. Em segundo lugar, ao opor o PFL ao PMDB de Requião (em coligação com o PT) iniciou o lento alinhamento dos principais partidos estaduais à polarizaçáo nacional.

Além de selar a saída definitiva de Jaime Lerner do cenário político estadual, o primeiro turno de 2002 não teve a polarização das corridas anteriores. Muitos partidos lançaram candidatos com potencial de chegar ao segundo turno: Álvaro Dias (que trocou novamente de partido e, agora no PDT) terminou o primeiro turno com $38 \%$ dos votos. Roberto Requião terminou o primeiro turno com $26 \%$ dos votos. Ainda tiveram expressiva votação: Beto Richa (PSDB) com 17\%, Padre Roque do PT com 16\% e Rubens Bueno (PPS - Partido Popular Socialista) com 7\%. Após o segundo turno e ajudado pela aliança informal com a campanha vencedora de Lula à presidência, Requião venceu Álvaro Dias no segundo turno.

A reeleição de Requião em 2006 acontece com um fato extraordinário: seu opositor, o senador Osmar Dias (do PDT, irmão de Álvaro Dias), chega ao segundo turno com relativo descrédito e adquire expressiva adesão, a ponto da disputa ser resolvida com apenas $0,1 \%$ dos votos em favor de Requiáo no final de outubro daquele ano.

Terminado o terceiro mandato de Roberto Requião e o quinto do PMDB no Palácio Iguaçu, as eleiçóes de 2010 colocaram em confronto o ex-prefeito de Curitiba, Beto Richa (PSDB) e o Senador Osmar Dias (PDT), com o Richa vencendo no primeiro turno com $52 \%$ dos votos. Além da chegada dos tucanos ao governo estadual paranaense (fato até então inédito), essa competição posicionou novamente o PDT ao lado dos partidos de centro-esquerda, candidatura que teve influência direta dos ministros trabalhistas e da tradicional aliança PT-PDT no plano nacional. Assim, após intensa trajetória entre os polos da direita, centro e esquerda no interior dos blocos suprapartidários paranaenses, essa posição de alinhamento à aliança nacional emerge como um sinal claro de estruturação do sistema partidário 
paranaense em direção a um comportamento mais verticalizado e consistente com o sistema nacional.

Essa história demonstra um claro predomínio das figuras consagradas da política paranense: José Richa, Álvaro Dias, Roberto Requião, Jaime Lerner e Beto Richa foram os governadores desde o reestabelecimento de eleiçôes diretas para o executivo estadual. Entretanto, como se pode notar pela Tabela 2, essa história está assentada sobre um sistema partidário estruturado em poucas forças políticas.

Tabela 2 - Resultados eleitorais para governo estadual do Paraná no $1^{\circ}$ turno (1982-2010)

\begin{tabular}{|c|c|c|c|c|c|c|c|c|}
\hline & \multicolumn{3}{|c|}{ Vencedor } & \multicolumn{3}{|c|}{$2^{\circ}$ colocado } & \multicolumn{2}{|c|}{10 turno } \\
\hline Eleição & Nome & Partido & $\begin{array}{c}\% \\
\text { votos }\end{array}$ & Nome & Partido & $\begin{array}{c}\% \\
\text { votos }\end{array}$ & $\begin{array}{l}\text { Soma } \\
10+2^{o}\end{array}$ & $\begin{array}{l}\text { Tipo da } \\
\text { disputa }\end{array}$ \\
\hline 1982 & José Richa & PMDB & 59,26 & Saul Raiz & PSD & 39,01 & 98,27 & Polarizada \\
\hline 1986 & $\begin{array}{c}\text { Álvaro } \\
\text { Dias }\end{array}$ & PMDB & 70,7 & $\begin{array}{l}\text { Alencar } \\
\text { Furtado }\end{array}$ & PMB & 24 & 94,7 & Predominante \\
\hline 1990 & $\begin{array}{l}\text { Roberto } \\
\text { Requião }\end{array}$ & PMDB & 44,3 & $\begin{array}{c}\text { Carlos } \\
\text { Martinez }\end{array}$ & PRN & 35,15 & 79,45 & $\begin{array}{c}\text { Não } \\
\text { polarizada }\end{array}$ \\
\hline 1994 & $\begin{array}{l}\text { Jaime } \\
\text { Lerner }\end{array}$ & PDT & 54,85 & Álvaro Dias & PP & 38,55 & 93,4 & Polarizada \\
\hline 1998 & $\begin{array}{l}\text { Jaime } \\
\text { Lerner }\end{array}$ & PFL & 52,21 & $\begin{array}{l}\text { Roberto } \\
\text { Requião }\end{array}$ & PMDB & 45,91 & 98,12 & Polarizada \\
\hline 2002 & $\begin{array}{l}\text { Roberto } \\
\text { Requião }\end{array}$ & PMDB & 26,18 & Álvaro Dias & PDT & 31,4 & 57,58 & $\begin{array}{c}\text { Não } \\
\text { polarizada }\end{array}$ \\
\hline 2006 & $\begin{array}{l}\text { Roberto } \\
\text { Requião }\end{array}$ & PMDB & 42,8 & Osmar Dias & PDT & 38,6 & 81,4 & $\begin{array}{c}\text { Não } \\
\text { polarizada }\end{array}$ \\
\hline 2010 & $\begin{array}{l}\text { Beto } \\
\text { Richa }\end{array}$ & PSDB & 52,43 & Osmar Dias & PDT & 45,63 & 98,06 & Polarizada \\
\hline
\end{tabular}

Fonte: TSE (2013) e TRE-PR (2013).

Ao todo, quatro partidos governaram o estado. Contando todos os partidos que conseguiram ficarem primeiro ou segundo lugar desde a retomada da democracia, temos um total de oito partidos. Entretanto, desconsiderando a década de 1980 que apresentou um quadro de elevada indefinição do quadro partidário, a partir dos anos 90 o total de protagonistas fica resumido a cinco partidos (PMDB, PDT, PP, PFL e PSDB).

Das oito eleições realizadas no período quatro delas foram polarizadas no primeiro turno, demonstrando que a capacidade de outras organizaçóes apresentarem-se como terceira força robusta foi bastante limitada. Em somente três eleiçôes as disputas podem ser consideradas não polarizadas e contiveram candidatos 
capazes embaralhar a tradicional polarização entre um grupo de centro-esquerda e um grupo de centro-direita, mas longe de ameaçar predomínio dessas forças.

Dentre as "terceiras forças", tivemos apenas uma de peso, representada por José Richa em 1990, que fez cerca de $20 \%$ dos votos. Nas duas outras ocasióes de eleiçôes não polarizadas, em 2002 e 2006, a tendência foi a partilha dos votos não alinhados aos dois concorrentes principais (em três candidaturas em 2002 e em duas candidaturas em 2006). Isso parece estar associado menos a real intenção dessas siglas de conquistarem o executivo estadual e mais às suas estratégias para criar novas lideranças ou amealhar melhores condiçóes de participar de governos posteriores.

Não obstante a incipiente polarização, existem evidências que apontam na direção contrária. Duas são especialmente embaraçosas para a afirmação da polarização plena: i) a migração de nomes fortes entre partidos muito diferentes entre si no que se refere à posição ideológica nacional (os irmãos Dias e o próprio Lerner) e ii) a mudança de posição de partidos importantes perante essas frentes estaduais de centro-esquerda e centro-direita, notadamente o PDT que protagonizou quatro das oito eleições ao governo paranaense. Como podemos notar no Quadro 1, o PDT saltou entre os blocos muitas vezes, inclusive em eleiçóes consecutivas, apresentando uma trajetória estilo "zigue-zague" entre as famílias ideológicas durante praticamente todo o período. 
Quadro 1 - Partidos e coligações com mais de 5\% dos votos válidos no $1^{\circ}$ turno - Eleições majoritárias no Paraná (1982-2010)

\begin{tabular}{|c|c|c|c|c|c|c|c|c|}
\hline Eleiçáo & Disputa & \multicolumn{3}{|c|}{ Centro-esquerda } & \multicolumn{3}{|c|}{ Centro-direita } & $\mathrm{N}^{*}$ \\
\hline 1982 & $\begin{array}{c}\text { Richa } x \\
\text { Raiz }\end{array}$ & & & PMDB & & PDS & & 5 \\
\hline 1986 & $\begin{array}{l}\text { Álvaro } x \\
\text { Furtado }\end{array}$ & & & $\begin{array}{l}\text { PMDB - } \\
\text { PND }\end{array}$ & & $\begin{array}{c}\text { PDT - PFL - } \\
\text { PMD - PJ }\end{array}$ & & 7 \\
\hline 1990 & $\begin{array}{l}\text { Requião } \\
\text { x } \\
\text { Martinez }\end{array}$ & $\begin{array}{l}\text { PT - } \\
\text { PSB }\end{array}$ & $\begin{array}{l}\text { PMDB - } \\
\text { PMN - } \\
\text { PTdoB }\end{array}$ & $\begin{array}{l}\text { PSDB - } \\
\text { PCB - } \\
\text { PC do B }\end{array}$ & & & $\begin{array}{l}\text { PRN - } \\
\text { PFL - } \\
\text { PDC - } \\
\text { PSC }\end{array}$ & 6 \\
\hline 1994 & $\begin{array}{l}\text { Lerner x } \\
\text { Álvaro }\end{array}$ & & & $\begin{array}{c}\text { PMDB - } \\
\text { PP - PPR - } \\
\text { PMN }\end{array}$ & & $\begin{array}{c}\text { PDT - PTB - } \\
\text { PFL - PV - } \\
\text { PSDB }\end{array}$ & & 7 \\
\hline 1998 & $\begin{array}{l}\text { Lerner x } \\
\text { Requião }\end{array}$ & & $\begin{array}{c}\text { PDT - PC } \\
\text { do B - PV - } \\
\text { PCB - PAN } \\
\text { - PRTB - } \\
\text { PMN - } \\
\text { PSN - } \\
\text { PMDB - } \\
\text { PT }\end{array}$ & & & $\begin{array}{c}\text { PPB - PST - } \\
\text { PSC - PPS - } \\
\text { PRN - PSD - } \\
\text { PT do B - PRP - } \\
\text { PSB - PFL - PL - } \\
\text { PTN - PTB - } \\
\text { PSL }\end{array}$ & & 4 \\
\hline 2002 & $\begin{array}{l}\text { Requião } \\
\text { x Álvaro }\end{array}$ & $\begin{array}{l}\text { PT - } \\
\text { PHS - } \\
\text { PCB - } \\
\text { PC do B } \\
\text { - PL }\end{array}$ & PPS-PV & PMDB & $\begin{array}{c}\text { PDT - } \\
\text { PTB - } \\
\text { PTN - } \\
\text { PPB - PRP } \\
\text { - PT do B }\end{array}$ & $\begin{array}{l}\text { PSDB - PFL - } \\
\text { PSL - PAN }\end{array}$ & & 12 \\
\hline 2006 & $\begin{array}{l}\text { Requião } \\
\text { x Osmar }\end{array}$ & $\begin{array}{c}\text { PT - } \\
\text { PHS - } \\
\text { PL - } \\
\text { PAN - } \\
\text { PRB - } \\
\text { PCdoB }\end{array}$ & PV & $\begin{array}{l}\text { PMDB - } \\
\text { PSC }\end{array}$ & & $\begin{array}{c}\text { PP - PDT - PTB } \\
\text { - PTN - PMN - } \\
\text { PTC - PSB - } \\
\text { PRONA - } \\
\text { PT do B }\end{array}$ & $\begin{array}{l}\text { PPS - } \\
\text { PFL }\end{array}$ & 11 \\
\hline 2010 & $\begin{array}{l}\text { Beto } \mathrm{x} \\
\text { Osmar }\end{array}$ & & $\begin{array}{l}\text { PP - PDT - } \\
\text { PTB - PTN } \\
\text { - PMN - } \\
\text { PTC - PSB } \\
\text { - PRONA }\end{array}$ & & & $\begin{array}{c}\text { PRB - PP - PTB } \\
\text { - PSL - PTN - } \\
\text { PPS - DEM - } \\
\text { PSDC - PHS - } \\
\text { PMN - PTC - } \\
\text { PSB - PRP - } \\
\text { PSDB }\end{array}$ & & 7 \\
\hline
\end{tabular}

* $\mathrm{N}$ de candidatos

Nota: Os protagonistas alinhados aos polos estão em destaque gráfico (negrito). O PDT também foi destacado por representar a contra-face do padrão observado.

Fonte: TRE-PR (2013). 
Em 1986 e em 1994 os trabalhistas estiveram situados na frente de centrodireita. Em 1998 passou a compor a aliança de centro-esquerda. Em 2002 retorna para a centro-direta, onde permaneceu em 2006 para, em 2010, retornar à composição dos partidos de centro-esquerda. Além deste, o PPS também esteve nos dois lados das frentes suprapartidárias, mas seu movimento é coerente com o diretório nacional do partido, que abandonou a coalizão petista no primeiro mandato de Lula e passou à oposição nacional. Finalmente, partidos tradicionais e com representação parlamentar regular também apresentaram comportamento coligacional errático durante as eleições majoritárias estaduais, casos do PSB, PTB e PCdoB.

Por outro lado, quando reparamos as posições do PT e PMDB, pelo lado esquerdo; e as posiçôes do PSDB e do PFL/DEM, pelo lado direito, temos nítida constatação da consistência das posições adotadas por essas organizações ao longo de todo o período. A entrada do PSDB em 1990 se dá por meio de uma coalizão com partidos de centro-esquerda, mas tratou-se de uma exceção. A partir de 1994 os principais partidos do estado se acomodam em cantos opostos do tabuleiro políticoideológico, ressalvando-se o PDT, que atuou como o partido da conveniência às candidaturas pontuais que não logravam alinhamento pleno à polarização histórica.

\section{Conclusões}

O artigo procurou oferecer parâmetros para se analisar o sistema partidário no estado do Paraná desde a redemocratização e permite avançar algumas considerações. Em primeiro lugar, a despeito do excesso de personalismo que marcou as disputas para o governo estadual, estas não se deram de modo aleatório e nem tampouco foram produto de jogadas nas quais os partidos contaram pouco. Dois blocos antagônicos de partidos dominaram o cenário. A causa para essa polarização parece residir no "efeito estruturante" (MELO, 2010) exercido pelas eleições presidenciais e pela configuração de dois grupos suprapartidários que puderam se consolidar como alternativas de políticas (policies) no estado (PMDB/PT versus $\mathrm{PSDB} / \mathrm{DEM}$ ).

Não é possível, entretanto, concluir que dessa situação de estruturação e alinhamento decorra um subsistema partidário institucionalizado, especialmente porque esse conceito exige menor instabilidade quantitativa (estabilização do número de partidos, o que só ocorreria se a crescente fragmentação não ocorresse), somado a baixa movimentação das lideranças entre as agremiações e menor inconsistência no conjunto das sucessivas coligaçóes. Todos esses fatores somados produzem instabilidade das performances dos partidos entre as eleiçóes, contexto que pode 
colocar em discussão inclusive a definição de um sistema partidário estadual (MELO, 2010).

Como apontado pelos trabalhos dedicados à institucionalização do PFL e do PDT no estado, a sorte dessas agremiaçóes esteve intensamente associada as possibilidade de suas lideranças estarem à frente do executivo estadual (CERVI e CODATO, 2006; CERVI, 2006). Náo obstante, quando observados sob a perspectiva sistêmica, percebemos estruturação em dois polos, cada um capitaneado por dois partidos de modo estável, embora não sistemático. Estável porque suas alianças se mantiveram em praticamente todos os governos desde 1998. Não sistemático porque as duplas de partidos se distanciam ocasionalmente no interior de seus polos ideológicos: O PSDB e o PFL-DEM não estiveram formalmente coligados em duas das oito eleiçóes analisadas, mas à exceção de 1990, não ousaram se enfrentar no primeiro turno. Por sua vez, PT e PMDB estiveram com candidaturas puras em mais eleiçóes, mostrando que sua aliança se constitui em desdobramentos da luta eleitoral após o encerramento do primeiro turno. O PMDB lançou candidatos em todas as eleiçôes, a não ser em 1994 e 2010. O PT foi às eleiçôes com candidato próprio em seis das oito eleiçôes, mas esteve com o PMDB no segundo turno nas eleiçôes recentes (2002 e 2006).

O fluxo dos pequenos partidos entre esses dois blocos é constante ao longo do período, fruto de suas estratégias para conquistar cargos legislativos ou pleitear espaço em coalizões governistas. Normalmente, a atração para os pequenos é o partido que está no governo. Entretanto, são mudanças ocorridas nas franjas do sistema e não são suficientes para abalar o padrão geral que opóe os dois blocos em polos separados ao longo dos últimos 30 anos.

A história das disputas eleitorais ao governo paranaense colocou dois grupos de lideranças em lados opostos e a sua história se tornou a história dos partidos no estado: Roberto Requião e seus correligionários enfrentaram diferentes nomes da política paranaense, incluindo Martinez, José Richa, Jaime Lerner e os irmãos Dias (Álvaro e Osmar), acomodados em diversas forças partidárias de acordo com a conjuntura local. Embora o grupo de antagonistas de Requião tenha tido diversas siglas ao longo das eleições, predominaram as siglas identificadas com a coalizão de centro-direita da política nacional (PSD, PRN - Partido da Reconstrução Nacional e PFL, conforme a Tabela 2). A maior discrepância fica por conta do PDT que, além ter sido o partido de longo período de Lerner (o adversário histórico de Requiáo e da coalizão de centro-esquerda no Paraná), oscilou entre os dois grupos suprapartidários de modo incessante ao longo do período. 
De acordo com o nosso argumento, estruturação é decorrência da decantação de posições de grandes e médios partidos em relação aos demais da disputa. Dois são os vetores dessa decantação: a própria construção da identidade político-ideológica (que se dá por meio da oposição e diferenciação com um lado oposto, um antagonista) e o alinhamento ao contexto partidário nacional. Mas como é um sistema multipartidário e federalizado, é normal que ocorra, no plano subnacional, realinhamentos e entradas estratégicas de certos partidos a esses dois polos que sejam estranhas e não coerentes ao contexto nacional. Portanto, estruturação também contempla os referenciais de abertura e fechamento das oportunidades de entrada de novos partidos no sistema.

A formação da identidade dos grupos políticos paranaenses, isto é, aqueles que atuaram como policy-seeking no estado, produziu um par de oposições históricas que se acomodaram em dois blocos partidários. Assim como no contexto nacional, diversos elementos facilitaram a fragmentação e tornou a representação parlamentar menos concentrada, mas o protagonismo nas disputas estaduais ficou restrito aos partidos fortes do estado e é possível que essa polarização caminhe em direção ao alinhamento às alternativas de policies nacionais, PT e PSDB, fato que depende também da confirmaçáo do PMDB como partido catch all de centro como vem ocorrendo desde o encerramento do ciclo de Requião no executivo estadual.

—Luiz Domingos Costa é Professor do Centro Universitário Uninter nos cursos de Ciência Política e Relações Internacionais, Pesquisador do Núcleo de Pesquisa em Sociologia Politica Brasileira (NUSP) da Universidade Federal do Paraná (UFPR) e Doutorando em Ciência Política na UFPR. E-mail: luizdomingos@gmail.com

Bruno Bolognesi é Professor de Ciência Política na Universidade Federal da Integração Latino-Americana (UNILA), Editor Executivo da Revista Paraná Eleitoral, Editor Associado da Revista de Sociologia e Política e Pesquisador do Núcleo de Pesquisa em Sociologia Politica Brasileira (NUSP/ UFPR) e do Centro de Partidos Politicos Latino-Americanos (CEPLA/ UFSCar). E-mail: brunobolognesi@gmail.com 


\section{Referências}

AMES, Barry. Os entraves da democracia no Brasil. Rio de Janeiro: FGV, 2003.

BARDI, Luciano; MAIR, Peter. The parameters of party systems. Party Politics, v. 14, n. 02, p. $147-$ 166, 2008.

BOHN, Simone; FERREIRA, Denise. A volatilidade eleitoral nos estados: sistema partidário e democracia no Brasil. Revista de Sociologia e Política. v. 17, n. 33, p. 187-208. 2009.

CARMANI, Daniele. The nationalization of politics: the formation of national electorates and party systems in Western Europe. New York: Cambridge University Press, 2004.

CARREIRÃO, Yan. O sistema partidário brasileiro: um balanço das tendências recentes. In: $36^{\circ}$ Encontro Anual da ANPOCS, Águas de Lindóia, 2012.

CAVALCANTE, Pedro; TURGEON, Mathieu. Desproporcionalidade na representação legislativa: análise dos efeitos sobre o sistema partidário no Brasil. In: 36 Encontro Anual da ANPOCS, Águas de Lindóia, 2012.

CERVI, Emerson U. Os processos de institucionalização partidária no sistema político subnacional: PDT do Paraná entre 1987 e 2002. In: NAZZARI, Rosana K. (Org.). Partidos e Comportamento Político no Brasil. Cascavel: Edunioeste, 2006. p. 155-187.

CERVI, Emerson U.; CODATO, Adriano. Institucionalização partidária: uma discussão empírica a partir do caso do PFL do Paraná. In: CODATO, Adriano; SANTOS, Fernando J. (Orgs.). Partidos e eleiçóes no Paraná: uma abordagem histórica. Curitiba: TRE-PR, 2006. p. 245-274.

COLOMER, Joseph M. Son los partidos que eligen los sistemas electorales (o las leyes de Duverger cabeza a bajo). Revista Española de Ciencia Política, n. 09, p. 39-63, 2003.

CORTEZ, Rafael D. P. Eleiçôes Majoritárias e Entrada Estratégica no Sistema Partidário-Eleitoral Brasileiro (1989-2006). 2009. 160f. Tese (Doutorado em Ciência Política) - Programa de Pós Graduação em Ciência Política, Universidade de São Paulo, São Paulo, 2009.

DUMONT, Patrick; CAULIER, Jean-François. The effective number of relevant parties: how voting power improves Laakso-Taagepera's index. Working Paper 2003/7, CEREC-FUSL, 2005. Disponível em: <http://centres.fusl.ac.be/CEREC/document/people/caulier/enrp.pdf> Acesso em: 18 dez. 2013.

DUVERGER, Maurice. Os partidos politicos. Brasília: UnB, 1980.

FERREIRA, Denise P.; BATISTA, Carlos M.; STABILE, Max. A evolução do sistema partidário brasileiro: número de partidos e votação no plano subnacional (1982-2006). Opiniáo Pública, v. 14, n. 2, p. 432-453, 2008.

LAAKSO, Markku; TAAGEPERA, Rein. Effective number of parties: a measure with applications to West Europe. Comparative Political Studies, v. 12, n. 01, p. 3-27, 1979.

LAPAlOMBARA, Joseph; WEINER, Myron. Political Parties and Political Development. Princeton: Princeton University Press, 1972.

LIMA Jr., Olavo B. O sistema partidário brasileiro: diversidades e tendências (1982-1994). Rio de Janeiro: Ed. FGV, 1997.

LEPRE, Mário S. Caos partidário paranaense. Londrina: Ed. UEL, 2000.

MAINWARING, Scott; PÉREZ-LINAAN, Aníbal. Topografia do Brasil profundo: votos, cargos e alinhamentos nos municípios brasileiros. Opiniáo Pública, v. 19, n. 01, p. 1-20, 2013.

. Why regions are important: regional specifities and region-wided iffusion of democracy. Kellog Working Papers, n. 322, 2005. Disponível em: <https://kellogg.nd.edu/publications/workingpapers/WPS/322.pdf>. Acesso em: 11 mar. 2014. 
MELO, Carlos R. F. Eleições presidenciais, jogos aninhados e sistema partidário no Brasil. Revista Brasileira de Ciência Política, n. 4, p. 13-41, 2010.

MENEGUELLO, Rachel. Sistema político, dinâmica partidária e a lógica de coalizões. In: IPEA. Estado, Instituiçôes e Democracia: democracia. v. 2. Brasília: Ipea, 2010. p. 127-160.

MIRANDA, Geralda. A influência da dinâmica eleitoral sobre o comportamento dos partidos na Câmara dos Deputados e no Senado Federal. Dados - Revista de Ciências Sociais, v. 52, n. 4, p. 911-959. 2009.

NICOLAU, Jairo M.; SCHMITT, Rogério. Sistema eleitoral e sistema partidário. Lua Nova, n. 36, p. 43-51, 1995.

OLIVEIRA, Ricardo C. Famílias, poder e riqueza: redes políticas no Paraná em 2007. Sociologias, n. 18, p. 150-169, 2007.

PEDERSEN, Mogens. The dynamics of European party systems: changing patterns of electoral volatility. European Journal of Political Research, v. 7, n. 01, p. 1-26, 1979.

REBELLO, Mauricio M. A fragmentação partidária no Brasil: visões e tendências. In: $36^{\circ}$ Encontro Anual da ANPOCS, Águas de Líndoia, 2012.

ROSE, Richard; MACKIE, Thomas. Do parties persist or fail? The big trade-off facing organizations. In: LAWSON, Kay; MERKL, Peter H. (Eds.), When Parties Fail. Princeton: Princeton University Press, 1988.

SAMUELS, David; ABRÚCIO, Fernando Luiz. Federalism and Democratic Transitions: The "New" Politics of the Governors in Brazil. Publius: The Journal of Federalism, v. 30, n. 2, p. 43-61, 2000.

SANTOS, André Marenco dos. Sedimentação de lealdades partidárias no Brasil: tendências e descompassos. Revista Brasileira de Ciências Sociais, v. 16, n. 45, p. 69-83, 2001.

SARTORI, Giovanni. Partidos e sistemas partidários. Rio de Janeiro: Zahar, 1982.

TAAGEPERA, Rein; SHUGART, Matthew S. Seats and votes: the effects and determinants of electoral systems. New Haven: Yale University Press, 1989.

TSE. Tribunal Superior Eleitoral. Disponível em: <www.tse.jus.br>. Acesso em: 29 nov. 2013.

TER-PR. Tribunal Regional Eleitoral do Paraná. Disponível em: <www.tre-pr.jus.br>. Acesso em: 01 dez. 2013.

Texto recebido em 31 de dezembro 2013. Aprovado em 07 de março de 2014. 
